\title{
Speech and swallowing characteristics in patients with facioscapulohumeral muscular dystrophy
}

\author{
Caracterização da fala e da deglutição em pacientes \\ com distrofia muscular facioescapuloumeral
}

\author{
Vanessa Brzoskowski dos SANTOS ${ }^{1}$, Jonas Alex Morales SAUTE², Laís Alves JACINTO-SCUDEIRO², \\ Annelise AYRES ${ }^{4}$, Rafaela Soares RECH+4, Alcyr Alves de OLIVEIRA ${ }^{1}$, Maira Rozenfeld OLCHIK ${ }^{5}$
}

\begin{abstract}
Background: Although facial muscle weakness is common in patients with Facioscapulohumeral Muscular Dystrophy (FSHD), the literature is scarce on the speech and swallowing aspects. Objective: To investigate speech and swallowing patterns in FSHD and assess the correlation with clinical data. Methods: A cross-sectional study was conducted. Patients with clinical confirmation of FSHD and aged above 18 years were included and paired with healthy control individuals by age and gender. Individuals who had neurological conditions that could interfere with test results were excluded. The following assessments were applied:speech tests (acoustic and auditory-perceptual analysis); swallowing tests with the Northwestern Dysphagia Patient Check Sheet (NDPCS), the Eat Assessment Tool (EAT-10), the Speech Therapy Protocol for Dysphagia Risk (PARD), and the Functional Oral Intake Scale (FOIS); disease staging using the modified Gardner-Medwin-Walton scale (GMWS); and quality of life with the Medical Outcomes Study 36-Item Short-Form Health Survey (SF-36). The correlation between test results and clinical data was verified by non-parametric statistics. Results: Thirteen individuals with FSHD and 10 healthy controls were evaluated. The groups presented significant differences in the motor bases of phonation and breathing. Regarding swallowing, two (15\%) individuals presented mild dysphagia and seven (53.8\%) showed reduced facial muscles strength. These results were not correlated with duration of the disease, age at symptoms onset, and quality of life. Dysphagia was related to worsening disease severity. Conclusions: FSHD patients presented mild dysarthria and dysphagia. Frequent monitoring of these symptoms could be an important way to provide early rehabilitation and better quality of life.
\end{abstract}

Keywords: Muscular Dystrophy, Facioscapulohumeral; Dysarthria; Speech; Deglutition Disorders; Neuromuscular Diseases.

\section{RESUMO}

Antecedentes: Embora haja predomínio de fraqueza muscular facial na distrofia facioescapuloumeral (FSHD), é escassa a literatura sobre aspectos de fala e deglutição. Objetivo: Investigar os padrões de fala e deglutição na FSHD e correlacioná-los com dados clínicos da doença. Métodos: Estudo transversal. Pacientes com confirmação clínica de FSHD e idade acima de 18 anos foram incluídos e pareados por idade e sexo com controles saudáveis. Foram excluídos indivíduos que apresentassem condições neurológicas que pudessem interferir nos resultados dos testes. Aplicaram-se as seguintes avaliações: fala (análise acústica e perceptivo-auditiva); deglutição, por meio do Northwestern Dysphagia Patient Check Sheet (NDPCS), Eat Assessment Tool (EAT-10), Protocolo de Avaliação para Risco de Disfagia (PARD) e Functional Oral Intake Scale (FOIS); estadiamento da doença, por meio da Gardner-Medwin-Walton scale (GMWS); e qualidade de vida, com o Medical Outcomes Study 36-Item Short-Form Health Survey (SF-36). Resultados de fala e deglutição foram correlacionados com dados clínicos da doença por teste não paramétrico. Resultados: Foram avaliados 13 indivíduos com FSHD e dez controles saudáveis. Houve diferença significativa entre os grupos nas bases motoras fonação e respiração. Na deglutição, dois (15\%) indivíduos apresentaram disfagia leve e sete (53,8\%), força reduzida da musculatura da face. Esses resultados não foram correlacionados com tempo de doença, idade de início dos sintomas e qualidade de vida. A disfagia esteve relacionada com a gravidade da doença. Conclusões: Pacientes com FSHD apresentaram disartria e disfagia leves. O monitoramento frequente desses sintomas pode ser uma forma importante de proporcionar reabilitação precoce e melhor qualidade de vida.

Palavras-chave: Distrofia Muscular Facioescapuloumeral; Disartria; Fala; Transtornos de Deglutição; Doenças Neuromusculares.

\footnotetext{
'Universidade Federal de Ciências da Saúde de Porto Alegre, Programa de Pós-Graduação em Ciências da Reabilitação, Porto Alegre RS, Brazil.

${ }^{2} U$ niversidade Federal do Rio Grande do Sul, Departamento de Medicina Interna, Porto Alegre RS, Brazil.

${ }^{3}$ Universidade Federal do Rio Grande do Sul, Porto Alegre RS, Brazil.

${ }^{4}$ Universidade Federal de Ciências da Saúde de Porto Alegre, Porto Alegre RS, Brazil.

${ }^{5}$ Universidade Federal do Rio Grande do Sul, Departamento de Cirurgia e Ortopedia, Porto Alegre RS, Brazil.

VBS (D) https://orcid.org/0000-0002-2322-3499; JAMS (D) https://orcid.org/0000-0003-1141-6573; LAJS (D) https://orcid.org/0000-0003-2567-5322; AA (D) https://orcid.org/0000-0003-3205-3660; RSR (DD https://orcid.org/0000-0002-3207-0180; AAO (D) https://orcid.org/0000-0002-0747-7835; MRO (D) https://orcid.org/0000-0002-8732-9225

Correspondence: Maira Rozenfeld Olchik; Email: mairarozenfeld@hotmail.com.

Conflict of interest: There is no conflicts of interest to declare.

Authors' contributions: VBS: study conduction, data collection, manuscript writing and final review; RSR: data analysis and manuscript writing; LAJS, AA: manuscript writing and review; MRO, JMS: study conception and design and final review of the manuscript; AAO: writing and revision of the final manuscript. Support: This study received funding from the Brazilian government through the master scholarship kindly awarded to Vanessa Brzoskowski dos Santos by the Coordenação de Aperfeiçoamento de Pessoal de Nivel Superior (CAPES).
}

Received on February 18, 2021; Received in its final form on July 04, 2021; Accepted on July 31, 2021. 


\section{INTRODUCTION}

Facioscapulohumeral Muscular Dystrophy (FSHD) is a genetic neuromuscular disease characterized by muscle weakness and progressive atrophy ${ }^{1,2}$. FSHD is one of the most frequent forms of muscular dystrophy in adults, with an estimated prevalence between four and ten per 100,000 population ${ }^{3}$. This disease primarily affects the facial muscles, scapula muscles, and humerus muscles ${ }^{4}$. One of the classical symptoms is weakness of the facial muscles, which is present in $80 \%$ of patients with FSHD, with the orbicularis and the greater zygomatic muscles being the most affected ${ }^{5,6}$. Although face muscular weakness is common in these individuals, the literature is scarce with regard to the speech (dysarthria) and swallowing (dysphagia) aspects.

Dysarthria is a speech disorder resulting from disturbances in neuromuscular control of speech mechanisms, which may compromise the functions of breathing, phonation, resonance, articulation, and prosody ${ }^{7}$. In a recent study, decreasing strength of facial muscles was found to be related to communication difficulties in patients with $\mathrm{FSHD}^{8}$. Despite the speech difficulty noted by these patients, very little is known about the characteristics of their dysarthria in FSHD, and its correlation with the clinical profile of the disease.

Dysphagia is a swallowing disorder caused by neurological disease and/or an obstruction that causes difficulty in safe deglutition from the mouth to the esophagus. The literature about dysphagia in FSHD is also scare and most relates to its incidence. The prevalence of dysphagia in FSHD ranges from 2 to $25 \%$, and it is usually characterized by a mild dysphagia that occurs in advanced stages ${ }^{10-13}$. In a study conducted with eight FSHD patients, six of them had mild dysphagia with fragmented swallowing and weakness of the tongue and jaw muscles ${ }^{11}$.

AS there are no publications in the literature on the standardized, objective and detailed characterization of speech and swallowing aspects in FSHD, further studies in this area are needed to better understand the disease, and support the early rehabilitation of these individuals. Thus, the aim of this study was to characterize speech and swallowing patterns in patients with FSHD, and assess their correlation with clinical data on the severity of the disease.

\section{METHODS}

\section{Study design and population}

This was a cross-sectional study conducted at a neuromuscular genetic disease care center within a hospital in Porto Alegre, in the southern region of Brazil, from April to November 2019. Unrelated and healthy controls, matched for age and sex, were recruited from the community.

The inclusion criteria were:

- Clinical diagnosis of FSHD.

- Aged 18 years or over.
The exclusion criteria were:

- Presence of other neurological or systemic conditions that can impact speech and swallowing patterns (for example, head and neck tumor).

- Unsuccessful attempt at telephone contact.

- Individuals who did not show up for the scheduled appointment.

- Patients who refused to participate in the study.

Initially, 26 patients with FSHD were recruited from the database of the care center at the hospital, 13 of which were excluded for the following reasons: five due to contact failure, four due to missing scheduled appointment, three refused to participate in the study, and one was under 18 years of age. The final sample of the study comprised 13 individuals (seven families) with FSHD.

The project was approved by the hospital's Research Ethics Committee. All participants gave their written consent before participating in the study.

\section{Data collection}

Individual with FSHD underwent assessments and answered the following questionnaires:

- Sociodemographic questionnaire: a structured questionnaire to collect general patient data, such as age, sex, education level, age of onset of symptoms, and duration of illness.

- Gardner-Medwin-Walton (GMWS): a clinical scale to quantify the neurological severity of FSHD. The instrument is divided into $10(0-9)$ increasing severity levels ${ }^{14}$.

- Medical Outcomes Study 36-Item Short-Form Health Survey (SF-36): a quality of life assessment instrument consisting of 8 dimensions: physical function, role-physical, bodily pain, general health, vitality, social function, role-emotional and mental health. Each dimension can be scored between 0 to 100 with higher scores indicating better health ${ }^{15}$.

- Mini-Mental State Examination (MMSE): screening test translated and validated for the Brazilian population. The cutoff used for formal education is 28 points for more than 8 years; 26 points for 5 and 8 years; 25 points for 1 and 4 years; and 20 points for illiterate ${ }^{16}$.

\section{Speech assessment}

- Speech assessment: this evaluation involves tasks to test the five subsystems of speech: phonation (sustaining the vowel /a/ in a single breath), resonance (sustaining the vowel /a/ in a single breath), prosody (counting from 20 to 30); respiration (sustaining the vowel /a/ in a single breath), and articulation (alternating the sequence of syllables [pataka] as fast as personal capacity allowed, repeatedly in a single breath; alternating the sequence I-U [i:ju:], repeatedly in a single breath). The Audacity software version 2.3.2 was used to record 
patients in a soundproof environment with a KARSECT HT-9 microphone and an Andrea Pureaudio USB adapter positioned approximately $5 \mathrm{~cm}$ from the subject's lips.

- Perceptual-auditory speech analysis: for the auditory-perceptual analysis, five speech therapists blinded to the patients' diagnosis analyzed the recordings and classified each of the five speech subsystems as normal or altered (mild, moderate or severe). The speech therapists were trained and had a Kappa concordance coefficient greater than 0.90 .

- Speech acoustic analysis: the PRAAT 5.1 software (www. praat.org) was developed by linguists Paul Boersma and David Weenink and its focus is sound analysis through parameters such as frequency, wavelength, decibels, among others ${ }^{17}$. The representation of these aspects, normative values, and corresponding speech tasks are described in the Table 1.

\section{Swallowing assessment}

A drink of water $(100 \mathrm{~mL})$ was offered during the functional test and the following instruments were applied:

- Northwestern Dysphagia Patient Check Sheet (NDPCS): comprises a brief clinical and functional evaluation of swallowing consisting of 28 items divided into three parts: medical history and behavioral variables, gross motor function, and an oral motor test ${ }^{20}$.

- Eat Assessment Tool (EAT-10): evaluates the emotional impact and physical symptoms that swallowing problems may have on the individual's life, with a score ranging from 0 to 40; scores greater than 3 indicate a risk for oropharyngeal dysphagia ${ }^{21}$.

- Speech-Language Pathology Assessment for Dysphagia Risk (PARD): used to classify normality, mild dysphagia, mild to moderate dysphagia, moderate dysphagia, moderate to severe dysphagia, and severe dysphagia ${ }^{22}$.
- Intake Scale (FOIS): ranges from zero to seven, with a score of zero indicating that no oral diet is recommended and a score of seven indicating that a normal oral diet is recommended without restrictions ${ }^{23}$.

\section{Statistical analysis}

The independent variables, the perceptual speech analysis, and the swallowing evaluation were presented through descriptive analyzes (absolute and relative frequencies and mean and standard deviation or median and interquartile range). The statistical test was selected according to the data distribution provided by the Shapiro-Wilk test and histograms. For the acoustic analysis of speech between groups, the Mann-Whitney test was used and for the correlation of speech scores with independent variables, the Spearman correlation test was used. Statistical significance was defined as $\mathrm{p}<0.05$. The statistical software used was SPSS version 22.0.

\section{RESULTS}

Thirteen individuals (seven families) with FSHD and 10 healthy controls were enrolled. The mean duration of disease in the FSHD group was $6.7(\mathrm{SD}=5.9)$ years and six $(46.1 \%)$ individuals in this group showed a neurological severity of 4 in the GMWS scale. The FSHD group presented lower scores of quality of life in the dimensions of physical function, rolephysical, and bodily pain than the control group. Table 2 shows the clinical and demographic characteristics of individuals with FSHD and controls.

\section{Speech results}

Auditory-perceptual analysis of the subsystems of speech of the FSHD and control groups are shown in Table 3. A statistical difference was found between the FSHD and control

Table 1. Acoustic evaluation: motor bases, tasks performed, and outcomes.

\begin{tabular}{|c|c|c|}
\hline Motor base & Assignment & Resulting variable \\
\hline Phonation & $\begin{array}{l}\text { Sustaining the A vowel in a } \\
\text { single breath. }\end{array}$ & $\begin{array}{l}\text { Fundamental frequency (Fo): For Brazilian Portuguese speakers, the frequency range } \\
\text { of normality for females is } 150-250 \mathrm{~Hz} \text { and } 80-150 \mathrm{~Hz} \text { for males }{ }^{18} \text {. } \\
\text { Jitter rap: The normative values of PRAAT is } 0.680 \% \text { as a threshold for pathology for } \\
\text { jitter rap }{ }^{17} \text {. } \\
\text { Shimmer local: The normative values of PRAAT is } 3.810 \% \text { as a threshold for pathology } \\
\text { for shimmer local }{ }^{17} \text {. }\end{array}$ \\
\hline Resonance & $\begin{array}{l}\text { Sustaining the A vowel in a } \\
\text { single breath. }\end{array}$ & Extraction of the third and fourth formants of sustained vowel A. \\
\hline Prosody & Counting from 20 to 30 & $\begin{array}{l}\text { Fundamental frequency of count: maximum fundamental frequency (Fo max), } \\
\text { minimum fundamental frequency (Fo min), and standard deviation of fundamental } \\
\text { frequency. }\end{array}$ \\
\hline Breathing & $\begin{array}{l}\text { Sustaining the A vowel in a } \\
\text { single breath. }\end{array}$ & $\begin{array}{l}\text { Maximum phonation time (MPT): For Brazilian Portuguese speakers, the standard of } \\
\text { normality for females is } 14 \text { seconds and for males, } 20 \text { seconds }{ }^{18} \text {. }\end{array}$ \\
\hline Articulation & $\begin{array}{l}\text { Alternating repetition of [pataka] } \\
\text { the fastest in a single breath. } \\
\text { Repetition diphthong I-U [i:ju:] } \\
\text { alternately in a single breath. }\end{array}$ & $\begin{array}{l}\text { Diadochokinesis (DDK): Young adults } 6.58 \text { syllables per second and elderly people, } \\
6.13 \text { syllables per second }{ }^{19} \text {. } \\
\text { Extraction of the first and the second formants of repetition of two combined vowels. }\end{array}$ \\
\hline
\end{tabular}


Table 2. Demographic data of the FSHD and control groups.

\begin{tabular}{|c|c|c|c|c|}
\hline & & FSHD $(n=13)$ & Controls $1(n=10)$ & $p$-value \\
\hline Female & & $9(69.2 \%)$ & $6(60 \%)$ & 0.663 \\
\hline Age & & $49.5(13.2)$ & $45.6(12.2)$ & 0.474 \\
\hline Educational level (years) & & $8.6(4.1)$ & - & \\
\hline Age of disease onset & & $42.7(15.9)$ & - & \\
\hline Disease duration & & $6.7(5.9)$ & - & \\
\hline \multirow{10}{*}{ GMWS - severity level } & Normal - 0 & $1(7.7 \%)$ & \multirow{10}{*}{-} & \\
\hline & 1 & $2(15.4 \%)$ & & \\
\hline & 2 & $0(0 \%)$ & & \\
\hline & 3 & $0(0 \%)$ & & \\
\hline & 4 & $6(46.1 \%)$ & & \\
\hline & 5 & $2(15.4 \%)$ & & \\
\hline & 6 & $1(7.7 \%)$ & & \\
\hline & 7 & $0(0 \%)$ & & \\
\hline & 8 & $1(7.7 \%)$ & & \\
\hline & Severe- 9 & $0(0 \%)$ & & \\
\hline \multirow{2}{*}{ MMSE } & Normal & $6(46.1 \%)$ & & \\
\hline & Altered & $7(53.9 \%)$ & & \\
\hline \multirow{8}{*}{ SF-36 } & Physical Function & $30(7.5-45.0)$ & & \\
\hline & Role-Physical & $0(0-62.5)$ & & \\
\hline & Bodily Pain & $21(15-46)$ & & \\
\hline & General Health & $27(26-48.5)$ & & \\
\hline & Vitality & $60(25-65)$ & & \\
\hline & Social Function & $50(31.2-75)$ & & \\
\hline & Role-Emotional & $33.50(0-83.2)$ & & \\
\hline & Mental Health & $76(42-89)$ & & \\
\hline
\end{tabular}

Data are reported means (standard deviation), except for sex, MMSE, and GMWS scores which are reported as frequency. SF-36 data are reported as medians (interquartile range). FSHD: Facioscapulohumeral muscular dystrophy; GMWS: Gardner-Medwin and Walton Scale; MMSE: Mini Mental State Examination; SF36: Medical Outcomes Study 36-Item Short-Form Health Survey.

Table 3. Auditory-perceptual analysis.

\begin{tabular}{lcccc} 
& \multicolumn{2}{c}{ Controls } \\
\cline { 2 - 5 } & $(\mathrm{n}=13)$ & Classification & $(\mathrm{n}=10)$ & Classification \\
\hline Phonation & $6(46.2 \%)$ & Mild impairment & $1(7.7 \%)$ & Mild impairment \\
Respiration & $1(7.7 \%)$ & Mild impairment & $0(0 \%)$ & - \\
Resonance & $1(7.7 \%)$ & Mild impairment & $0(0 \%)$ & - \\
Articulation & $3(23.1 \%)$ & Mild impairment & $0(0 \%)$ & - \\
Prosody & $0(0 \%)$ & - & $0(0 \%)$ & - \\
\hline
\end{tabular}

Data are expressed as frequency. FSHD: Facioscapulohumeral muscular dystrophy.

groups regarding the phonation and respiration subsystems (Table 4). The speech data from the acoustic analysis did not show a significant correlation with GMWS scores, duration of the disease, age at onset of symptoms, or the quality of life of these individuals.

Due to sex difference in fundamental frequency of speech, the acoustic analysis was performed between groups of females only. Only the respiration subsystem showed a significant difference between female FSHD and control participants [5.95 (3.72-7.50) and 9.37 (8.46-11.45), p=0.009].
The speech acoustic in males was not performed because of the small sample size (there were only four male participants with FSHD). This result did not have a significant correlation with the clinical data (Table 5).

\section{Swallowing results}

NDPCS results were verified to identify items that showed the greatest changes. Seven (53.8\%) patients presented altered oral muscle tone while nine (69.2\%) demonstrated no pharyngeal contraction of the gag reflex. Also, six 
Table 4. Comparison of acoustic parameters between groups.

\begin{tabular}{|c|c|c|c|}
\hline & FSHD $(n=13)$ & Controls $1(n=10)$ & p-value \\
\hline Jitter (local) & $0.70 \%(0.44-1.23)$ & $0.33 \%(0.23-0.75)$ & $0.044^{\star}$ \\
\hline Jitter (rap) & $0.36 \%(0.21-0.65)$ & $0.18 \%(0.11-0.39)$ & $0.032^{*}$ \\
\hline Shimmer (local) & $10.79 \mathrm{~dB}(8.72-14.39)$ & $7.90 \mathrm{~dB}(4.72-10.43)$ & $0.030 *$ \\
\hline FF average vowel & $161.02 \mathrm{~Hz}(127.23-191.91)$ & $162.03 \mathrm{~Hz}(111.55-207.98)$ & 0.951 \\
\hline FF minimum vowel & $125.12 \mathrm{~Hz}(93.35-168.20)$ & $94.64 \mathrm{~Hz}(76.92-155.36)$ & 0.264 \\
\hline FF maximum vowel & $251.18 \mathrm{~Hz}(171.20-403.76)$ & $215.16 \mathrm{~Hz}(129.90-411.85)$ & 0.804 \\
\hline FF SD vowel & $18.86 \mathrm{~Hz}(3.50-59.85)$ & $20.38 \mathrm{~Hz}(1.11-47.56)$ & 0.951 \\
\hline MPT vowela & $6.09(3.61-9.33)$ & $9.37(8.28-12.25)$ & $0.047 *$ \\
\hline FF average counting & $187.96 \mathrm{~Hz}(144.01-216.71)$ & $168.28 \mathrm{~Hz}(99.62-186.10)$ & 0.094 \\
\hline FF minimum counting & $77.13 \mathrm{~Hz}(73.69-92.82)$ & $80.24 \mathrm{~Hz}(77.24-85.89)$ & 0.620 \\
\hline FF maximum counting & $442.60 \mathrm{~Hz}(348.69-487.03)$ & 445.17Hz (253.37-491.90) & 0.710 \\
\hline FF SD counting & $70.45 \mathrm{~Hz}(39.96-84.77)$ & $39.17 \mathrm{~Hz}(20.93-58.32)$ & 0.063 \\
\hline PATAKA ${ }^{a}$ & $5.59(4.73-6.07)$ & $5.62(4.61-6.45)$ & 0.852 \\
\hline$I^{a}$ & $0.88(0.81-0.98)$ & $0.95(0.83-1.24)$ & 0.336 \\
\hline IU F1 & $523.04 \mathrm{~Hz}(457.17-570.53)$ & $510.80 \mathrm{~Hz}(470.88-622.22)$ & 0.598 \\
\hline IU F2 & $1752.25 \mathrm{~Hz}(1671.29-1823.87)$ & $1836.56 \mathrm{~Hz}(1614.20-1904.91)$ & 0.251 \\
\hline IU F3 & $2964.16 \mathrm{~Hz}(2807.62-3095.68)$ & $2983.76 \mathrm{~Hz}(2856.18-3038.25)$ & 0.687 \\
\hline IU F4 & $4032.51 \mathrm{~Hz}(3939.74-4112.93)$ & $3926.34 \mathrm{~Hz}(3833.21-4030.95)$ & 0.114 \\
\hline
\end{tabular}

Data are reported as medians (interquartile range); ${ }^{p}<0.05$; FSHD: Facioscapulohumeral muscular dystrophy; FF: Fundamental Frequency; MPT: maximum phonation time; asyllables per second.

Table 5. Correlations between speech disorders, clinical variables, and quality of life.

\begin{tabular}{|c|c|c|c|c|c|c|c|c|}
\hline & \multicolumn{2}{|c|}{ Jitter (local) } & \multicolumn{2}{|c|}{ Jitter (rap) } & \multicolumn{2}{|c|}{ Shimmer (local) } & \multicolumn{2}{|c|}{ MPT } \\
\hline & $p$-value & $r$ & $p$-value & $r$ & $p$-value & $r$ & $p$-value & $r$ \\
\hline Initial symptoms & 0.127 & - & 0.066 & - & 0.072 & - & 0.129 & - \\
\hline Length of illness & 0.128 & - & 0.249 & - & 0.053 & - & 0.868 & - \\
\hline GMWS & 0.406 & - & 0.738 & - & 0.603 & - & 0.334 & - \\
\hline SF-36 Physical Function & 0.665 & - & 0.411 & - & 0.485 & - & 0.559 & - \\
\hline SF-36 Role-Physical & 0.983 & - & 0.657 & - & 0.622 & - & 0.991 & - \\
\hline SF-36 Bodily Pain & 0.114 & - & 0.073 & - & 0.110 & - & 0.355 & - \\
\hline SF-36 General Health & 0.053 & - & 0.053 & - & 0.151 & - & 0.437 & - \\
\hline SF-36 Vitality & 0.872 & - & 0.843 & - & 0.760 & - & 0.914 & - \\
\hline SF-36 Social Function & 0.408 & - & 0.188 & - & 0.636 & - & 0.328 & - \\
\hline SF-36 Role-Emotional & 0.199 & - & 0.107 & - & 0.092 & - & 0.668 & - \\
\hline SF-36 Mental Health & 0.964 & - & 0.552 & - & 0.324 & - & 0.205 & - \\
\hline
\end{tabular}

MPT: maximum phonation time; GMWS: Gardner-Medwin and Walton Scale; SF-36: Medical Outcomes Study 36-Item Short-Form Health Survey.

(46.1\%) presented deviated lip protrusion and nine $(69.2 \%)$ reported not being able to move their lips, such as in pouting and whistling. Of the 13 patients with FSHD, two (15\%) were diagnosed with mild dysphagia. The average EAT-10 score was 1.15 ( \pm 1.86$)$. Regarding the functionality, $85 \%$ of the patients presented a FOIS 7 and 15\% were a FOIS 6 (15\%).

Regarding the NDPCS instrument, there was a positive correlation with the GMWS $(\mathrm{r}=0.604, \mathrm{p}=0.029)$, showing that the greater the neurological severity the higher the score on this instrument. When the two patients who had a diagnosis of mild dysphagia were individually analyzed, we found that both scored the highest values in the GMWS (eight and six). There was no correlation between the swallowing data from the NDPCS instrument with other clinical data and with quality of life: initial symptoms ( $\mathrm{p}=0.805)$; duration of illness $(\mathrm{p}=0.609)$; physical function $(\mathrm{p}=0.148)$; role-physical $(\mathrm{p}=0.186)$; bodily pain $(\mathrm{p}=0.869)$; general health $(\mathrm{p}=0.053)$; vitality $(\mathrm{p}=0.446)$; social function $(\mathrm{p}=0.753)$; role-emotional $(\mathrm{p}=547)$; and mental health $(\mathrm{p}=0.250)$. 


\section{DISCUSSION}

In this study, we carried out a detailed characterization of speech and swallowing in FSHD patients undergoing treatment at a neuromuscular genetic disease care center in southern Brazil. Almost half of the patients were diagnosed with mild dysarthria after auditory-perceptual and acoustic analysis of their speech, with changes in the phonation and respiration subsystems. We found mild dysphagia in $15 \%$ of the patients, and the risk for dysphagia observed with the EAT-10 is compatible with swallowing findings.

Almost half of the patients with FSHD had alterations in the motor base of phonation in the auditory-perceptual analysis when compared to the control group. In the acoustic analysis including both sexes, alterations in the motor bases of phonation and breathing were observed, corroborating the findings in the auditory-perceptual analysis. This indicates the importance of carrying out both analyzes, as the acoustic analysis proved to be complementary to the auditory analysis ${ }^{7}$. Auditory-perceptual analysis assesses the global impression of vocal quality and is considered the gold standard of analysis ${ }^{24}$.

Regarding the motor base of breathing, measured in the acoustic analysis by the maximum phonation time (MPT), patients with FSHD presented values well below normal and lower than the control group ${ }^{18}$. One hypothesis is that this reduction in maximum phonation time may be related to muscle fatigue and weakness ${ }^{8,25,26}$. FSHD patients have respiratory muscle weakness as an intrinsic characteristic of the disease, which can involve the diaphragm and expiratory abdominal muscles ${ }^{27}$. Clinically, these individuals can have communication difficulties and fatigue with long speeches. Additionally, breathing is closely related to phonation as it affects the synchrony between aerodynamic and myoelastic mechanisms, leading to coordination disorders in affected individual ${ }^{28}$.

In the phonation subsystem, six (46.2\%) patients presented mild changes in the auditory-perceptual analysis. As in the acoustic analysis, patients with FSHD had significantly higher values for shimmer and jitter when compared to the control group. Changes in this motor base possibly also occur due to fatigue, muscle weakness, or breathing changes. These changes in vocal quality interfere with speech intelligibility and can have a critical impact on communication skills, which in turn limits the individual's occupational, educational and social abilities. Correct characterization of these changes can allow a more specific and early rehabilitation ${ }^{29}$.

Even though FSHD patients had reduced strength in facial muscles, impaired articulation was observed in three (21.3\%) patients. In the acoustic analysis, this motor subsystem was similar in patients and control groups. Diadochokinesis is widely used to measure the articulatory quality of neurological patients ${ }^{30}$. The initial hypothesis is that since this was a sample with a predominance of individuals with mild disease, joint damage may not yet have been apparent in this population.
In the swallowing evaluation, only $15 \%$ of the patients had mild oropharyngeal dysphagia, characterized by changes in the pharyngeal phase (delay in pharyngeal swallowing, reduction in pharyngeal elevation, and multiple swallowing). In a videofluoroscopy study, it was observed that the decrease in tongue strength in patients with FSHD is consistent with the delay in pharyngeal swallowing ${ }^{11}$. Changes in swallowing were related to worsening disease severity. These data are in line with the literature, where the reported prevalence of dysphagia in patients with FSHD ranges from 2 to $25 \%$, being generally characterized by mild dysphagia and occurring in more advanced cases of the disease $^{8,10-13}$.

The majority of patients had reduced strength of facial muscles and absence of the GAG reflex. These findings agree with those of other studies that mainly reported weakness of the tongue and jaw and decreased resistance to cheek compression $^{8,11}$. Patients presented deviated lip protrusion and reported not being able to make certain lip movements (such as puckering and whistling) and this may be related to the orbicularis oris and zygomaticus major muscles, which are the most affected muscles in these patients ${ }^{5}$.

Regarding the eating function, $85 \%$ of the patients maintained a normal oral diet (FOIS 7) and $15 \%$ had some food restriction (FOIS 6). The self-assessment of the risk for dysphagia of patients with FSDH measured by the EAT-10 was compatible with swallowing findings, demonstrating reliability in patients' self-perception, which may be useful in the early identification of symptoms.

It is important to note that there was no correlation between speech and swallowing changes with quality of life. This might indicate that the current mild changes might not impact quality of life. In addition, as changes were also unrelated to the duration of the disease and the age of onset of symptoms, they may not follow the course of the disease but occur at different times and require constant clinical attention to detect symptoms.

The main limitation of this work was the sample size and the lack of a molecular diagnosis of FSHD. Considering that previous reports suggest that FSHD-related D4Z4 contractions are responsible for $95 \%$ of FSHD cases, our results must be interpreted as mainly related to this subtype of the disease $^{3}$. Another limitation of this work relates to the lack of objective assessment of swallowing in these patients. The above findings show that the topic is relevant and would be best investigated longitudinally, to identify at what point in the course of the disease these changes occur and how they vary in the course of the disease.

In conclusion, FSHD patients had mild dysarthria (with changes in the phonation and respiration subsystems) and mild dysphagia, which is associated with disease severity. Thus, the frequent monitoring of these symptoms by physicians may be important to ensure early rehabilitation and a better quality of life for these patients. 
1. Wagner KR. Facioscapulohumeral muscular dystrophies. Continuum (Minneap Minn). 2019 Dec;25(6):1662-81. https://doi.org/10.1212/ CON.0000000000000801

2. Statland J, Tawil R. Facioscapulohumeral muscular dystrophy. Neurol Clin. 2014 Aug;32(3):721-8, ix. https://doi.org/10.1016/j. ncl.2014.04.003

3. Preston MK, Tawil R, Wang LH. Facioscapulohumeral Muscular Dystrophy. 1999 Mar 8 [updated 2020 Feb 6]. In: Adam MP, Ardinger HH, Pagon RA, Wallace SE, Bean LJH, Mirzaa G, et al., editors. GeneReviews ${ }^{\oplus}$. Seattle (WA): University of Washington, Seattle; 1993-2021. PMID: 20301616.

4. Greco A, Goossens R, van Engelen B, van der Maarel SM. Consequences of epigenetic derepression in facioscapulohumeral muscular dystrophy. Clin Genet. 2020 Jun;97(6):799-814. https://doi. org/10.1111/cge.13726

5. Mul K, Lassche S, Voermans NC, Padberg GW, Horlings CGC, van Engelen BGM. What's in a name? The clinical features of facioscapulohumeral muscular dystrophy. Pract Neurol. 2016 Jun;16(3):201-7. https://doi.org/10.1136/practneurol-2015-001353

6. Mul K, van den Boogaard ML, van der Maarel SM, van Engelen BGM. Integrating clinical and genetic observations in facioscapulohumeral muscular dystrophy. Curr Opin Neurol. 2016 Oct;29(5):606-13. https://doi.org/10.1097/WC0.0000000000000360

7. Ortiz KZ, Carrillo L. Comparação entre as análises auditiva e acústica nas disartrias. Rev Soc Bras Fonoaudiol. 2008;13(4):325-31. https:// doi.org/10.1590/S1516-80342008000400005

8. Mul K, Berggren KN, Sills MY, McCalley A, Van Engelen BGM, Johnson $\mathrm{NE}$, et al. Effects of weakness of orofacial muscles on swallowing and communication in FSHD. Neurology. 2019 Feb;92(9):e957-e963. https://doi.org/10.1212/WNL.0000000000007013

9. Baijens LWJ, Clavé P, Cras P, Ekberg O, Forster A, Kolb GF, et al. European society for swallowing disorders - European union geriatric medicine society white paper: Oropharyngeal dysphagia as a geriatric syndrome. Clin Interv Aging. 2016 Oct;11:1403-28. https:// doi.org/10.2147/CIA.S107750

10. Stübgen JP. Facioscapulohumeral muscular dystrophy: A radiologic and manometric study of the pharynx and esophagus. Dysphagia. 2008 Dec;23(4):341-7. https://doi.org/10.1007/s00455-007-9141-0

11. Wohlgemuth M, de Swart BJM, Kalf JG, Joosten FBM, van der Vliet AM, Padberg GW. Dysphagia in facioscapulohumeral muscular dystrophy. Neurology. 2006 Jun;66(12):1926-8. https://doi. org/10.1212/01.wnl.0000219760.76441.f8

12. Yamanaka G, Goto K, Matsumura T, Funakoshi M, Komori T, Hayashi YK, et al. Tongue atrophy in facioscapulohumeral muscular dystrophy. Neurology. 2001 Aug;57(4):733-5. https://doi.org/10.1212/ wnl.57.4.733

13. Statland JM, Tawil R. Risk of functional impairment in facioscapulohumeral muscular dystrophy. Muscle Nerve. 2014 Apr;49(4):520-7. https://doi.org/10.1002/mus.23949

14. Fanin M, Angelini C. Muscle pathology in dysferlin deficiency. Neuropathol Appl Neurobiol. 2002 Dec;28(6):461-70. https://doi. org/10.1046/j.1365-2990.2002.00417.x

15. Ciconelli RM, Ferraz MB, Santos W, Meinao I, Quaresma MR. Brazilian-Portuguese version of the SF-36. A reliable and valid quality of life outcome measure. Rev Bras Reumatol. 1999 MayJun;39(3):143-50.
16. Memória CM, Yassuda MS, Nakano EY, Forlenza O V. Brief screening for mild cognitive impairment: Validation of the Brazilian version of the Montreal cognitive assessment. Int J Geriatr Psychiatry. 2013 Jan;28(1):34-40. https://doi.org/10.1002/gps.3787

17. Boersma P, Weenink D. Praat, a system for doing phonetics by computer. Glot Int. 2001 Nov-Dec;5:341-5.

18. Behlau M, Azevedo R, Pontes P. Conceito de voz normal e classificação das disfonias. In: Behlau M. Voz: o livro do especialista. Rio Janeiro: Revinter; 2001. p. 53-79.

19. Padovani M, Gielow I, Behlau M. Phonarticulatory diadochokinesis in young and elderly individuals. Arq Neuro-Psiquiatr. 2009 Mar;67(1):58-61. https://doi.org/10.1590/s0004$282 \times 2009000100015$

20. Magalhães Junior HV, Pernambuco LA, Souza LBR, Ferreira MAF, Lima KC. Tradução e adaptação transcultural do Northwestern Dysphagia Patient Check Sheet para o português brasileiro. CoDAS. 2013;25(4):369-74

21. Gonçalves MIR, Remaili CB, Behlau M. Cross-cultural adaptation of the Brazilian version of the Eating Assessment Tool - EAT-10. CoDAS. 2013 Dec;25(6):601-4. https://doi.org/10.1590/S231717822013.05000012

22. Padovani A, Moraes D, Mangili L, Andrade C. Protocolo Fonoaudiológico de Avaliação do Risco para Disfagia (PARD). Rev Soc Bras Fonoaudiol. 2007 Sep;12(3):199-205. https://doi.org/10.1590/ S1516-80342007000300007

23. Crary MA, Carnaby Mann GD, Groher ME. Initial psychometric assessment of a functional oral intake scale for dysphagia in stroke patients. Arch Phys Med Rehabil. 2005 Aug;86(8):1516-20. https:// doi.org/10.1016/j.apmr.2004.11.049

24. Oates J. Auditory-perceptual evaluation of disordered voice quality: pros, cons and future directions. Folia Phoniatr Logop. 2009;61(1):49-56. https://doi.org/10.1159/000200768

25. Schipper K, Bakker M, Abma T. Fatigue in facioscapulohumeral muscular dystrophy: a qualitative study of people's experiences. Disabil Rehabil. 2017 Sep;39(18):1840-6. https://doi.org/10.1080/09 638288.2016 .1212109

26. Voet NBM, Bleijenberg G, Padberg GW, van Engelen BGM, Geurts ACH. Effect of aerobic exercise training and cognitive behavioural therapy on reduction of chronic fatigue in patients with facioscapulohumeral dystrophy: Protocol of the FACTS-2-FSHD trial. BMC Neurol. 2010 Jun;10:56. https://doi.org/10.1186/14712377-10-56

27. Henke C, Spiesshoefer J, Kabitz HJ, Herkenrath S, Randerath W, Brix T, et al. Respiratory muscle weakness in facioscapulohumeral muscular dystrophy. Muscle Nerve. 2019 Dec;60(6):679-86. https:// doi.org/10.1002/mus.26717

28. Lundy DS, Roy S, Xue JW, Casiano RR, Jassir D. Spastic/spasmodic vs. tremulous vocal quality: Motor speech profile analysis. J Voice. 2004 Mar;18(1):146-52. https://doi.org/10.1016/j.jvoice.2003.12.001

29. Hustad KC. Comprehension and intelligibility scores for speakers with dysarthria.J Speech Lang Hear Res. 2008 Jun;51 (3):562-73. https://doi.org/10.1044/1092-4388(2008/040)

30. Kumar S, Kar P, Singh D, Sharma M. Analysis of diadochokinesis in persons with Parkinson's disease. J Datta Meghe Inst Med Sci Univ. 2018 Jul;13(3):140-2. https://doi.org/10.4103/jdmimsu. jdmimsu_66_18 